\title{
Countermeasures to Improve Local Government Governance Capability by Using Big Data
}

\author{
Weigang Guo ${ }^{1, a^{*}}$, Zhen Zhu ${ }^{1, b}$, Xiaohua Li ${ }^{1, \mathrm{c}}$, Jianqin Xie ${ }^{1, \mathrm{~d}}$ and Qiuming Lin ${ }^{1, \mathrm{e}}$ \\ ${ }^{1}$ School of Electronic and Information Engineering of Foshan University, China \\ awgguo@qq.com, baugustjune@fosu.edu.cn, c380125779@qq.com \\ d34603770@qq.com, eqmlin8809@qq.com
}

\begin{abstract}
Keywords: Big data; Local government governance capability; Social governance; Government service; Market supervision; Economic operation monitoring
\end{abstract}

\begin{abstract}
As big data has become a national strategy in many countries, China's local governments are aware of the political significance of big data, social value and economic value. For the purpose of helping the local governments to accelerate the pace of development of big data, this paper adopts the method of case study and takes Foshan city of Guangdong province, a leading area of information technology application in China, as an example, and proposes the top-level design of government big data development and the countermeasures of how to use big data to improve governance capability. The top-level design of the big data development of local government includes: laws and rules about data sharing and opening, big data management organization, personnel training and introduction, government data governance system, information system upgrading and integration, awareness training of data sharing, data opening and data security, development of big data industry, and funds, etc. Based on the connotation of Chinese government governance, four major themes are put forward to improve local government governance capability with big data. The first is using big data to promote standardization and facilitation of government services. The second is to promote precision of social governance. The third is to facilitate the convenience of government commercial services. And the fourth is to promote the scientific level of macro control.
\end{abstract}

\section{Introduction}

Big data has become a very hot topic in recent years. It has been widely used in many fields of society and economy and has become a national strategy in many countries. Big data is playing a more and more important role in government governance. Domestic scholars believe that, the advanced information technology plays a supporting role in the credibility, execution and effectiveness of the administrative operation of the government. Through the emerging information technology to improve the government's structure, functions and management methods, the modernization level of government governance is improved [1, 2]. The main paths of big data boosting the ability of government governance are setting up data authorities, strengthening top-level design, learning from foreign experience, encouraging reform and innovation, formation of standards and legal system, etc. [3]. Some scholars have also put forward that in order to truly achieving the use of big data technology and big data resources to promote the modernization of local government governance capacity, we should change the ideas local government governance, speed up data technology research and talent training, promote internal restructuring and innovation, and encourage and support the public to participate in governance [4]. Many scholars have put forward their own views on the meaning of governance capability and its modernization [5,6]. The government's governance capability includes value shaping ability, resource concentration ability, network construction ability, process innovation ability and question response ability. The modernization of governance capability refers to a state with modern characteristics and modern social governance requirements [7]. The modernization of the governance capability of local governments should focus on three aspects of politics, economy and society, and avoid individual breakthroughs $[8,9]$. 
Chinese government governance usually contains three aspects. The first is that the government fully and properly performs its functions; improve the government administrative management on scientific, democratic and effective through the internal management of the optimization of the organizational structure of the government, improving government operation mode and process, and strengthening the government management ability. The second is that, as a "visible hand" in the market economy, the government improves macro-control, healthy operation of the market economy, and better play the role of the government, economic and market governance activities through the transformation of government functions. The Third is that, as the main body of social management, under the overall framework of the Party committee leadership, government responsibility, social coordination, public participation and rule of law, the government manages social and public affairs [10]. Based on the connotation of the above government governance, this paper proposed that, in order to use big data to enhance local government governance capabilities, first of all is to improve the top-level design of big data development, and then to apply big data from the following four themes: using big data to promote standardization and facilitation of government services; using big data to promote precision of social governance; using big data to facilitate the convenience of government commercial services; And using big data to promote the scientific level of macro control.

\section{Top-level Design of Local Government's Big Data Development}

The top-level design of big data development of local government should be performed according to the comprehensive development level of the city, as well as information technology development and application level. Taking Foshan city of Guangdong Province as a case, the main contents of the top-level design of local big data development are studied and designed in this paper.

Overview of Foshan Big Data Development. The overall informatization level of Foshan occupies a leading position in China. Foshan has excellent information infrastructure for big data application, and has launched government data integration, data sharing and data opening. The big data applications of several government departments are also unique. The big data industry chain is being formed. The main problems are including the lack of strong municipal big data leading organization, weak awareness of sharing data, the data sharing mechanism not really having been established, lack of talents who having both big data applications techniques and management skills, and the government's data governance system having not yet been formed.

Top-level Design Framework for Big Data Development in Foshan. According to the actual situation of Foshan and the level of information technology development, the top-level design of big data development in Foshan contains following eight parts. They are laws and rules about data sharing and opening, big data management organization, personnel training and introduction, government data governance system, information system upgrading and integration, awareness training of data sharing, data opening and data security, development of big data industry, and funds, respectively. The framework is shown in Figure 1.

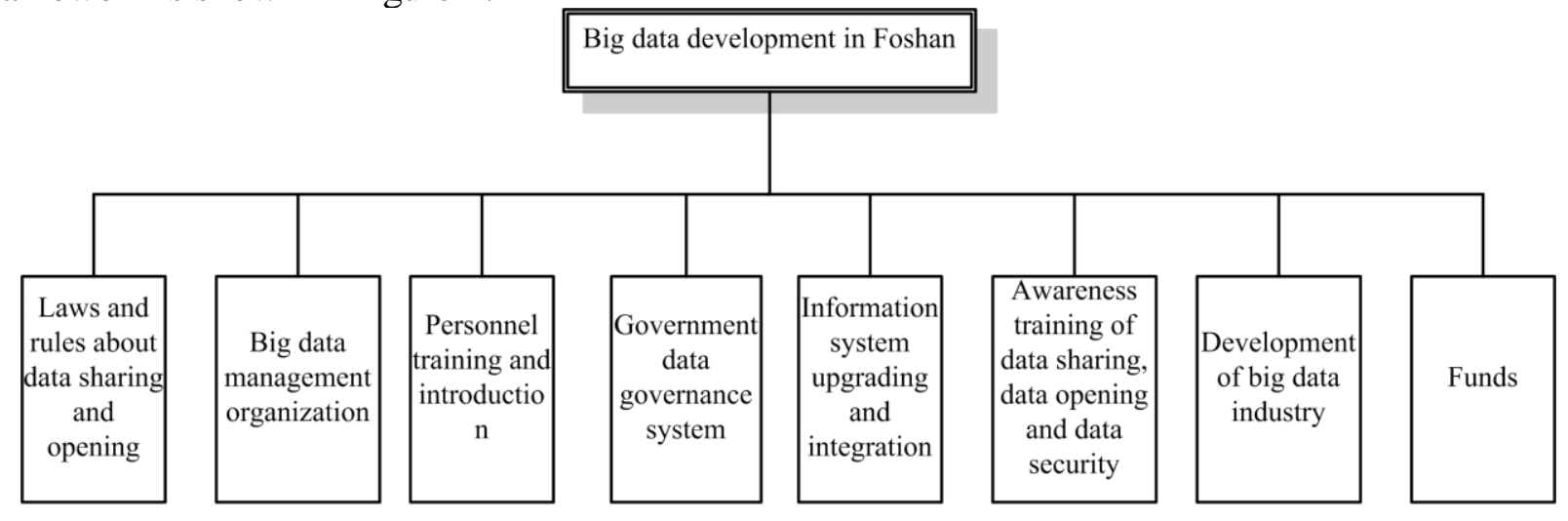

Figure 1. Top-level design framework for big data development in Foshan 
Strengthening the Construction of Laws and Rules about Data Sharing and Opening. Big data legislation should deal with the definition of big data, the definition of government information resources, data sharing, public institutions to collect data, data ownership, data transactions and data security and other aspects of the provisions. At the same time, the relevant illegal activities are defined and the legal liabilities of related violations are clearly defined.

Construction of a Powerful Big Data Management Organization. It is recommended that to establish the Foshan municipal network security and information technology leadership team, and set a big data management Bureau as the municipal government leadership department. it is proposed to set up a Consultative Committee on big data development in Foshan, consisting of domestic and local experts, to provide policy advice for the development, application and implementation of big data related projects in Foshan.

Strengthening the Training and Introduction of Big Data Talents. Efforts should be made to train and introduce information technology talents inside the government and professional personnel with big data thinking. So that the government can use social forces to carry out big data applications, but also to ensure the safety and control of business data. At the same time, the government should encourage local colleges and universities to set up big data related disciplines, to speed up training technical personnel to adapt to Foshan big data development and application.

Constructing government data governance system to ensure data quality from the source. The government data governance system is constructed from the four dimensions of strategy, mechanism, project and implementation. The strategy must include business development goals, IT planning, and data governance related development planning. And it is carried out through the organization, the system, the process construction and the implementation. Topics should include data standards, data governance, metadata, master data, data life cycles, and so on. It can be implemented by means of technology and management.

Implementation of the three year upgrading and integration plan of information system, providing technical support for big data applications. The municipal government formulates standards and norms, and co-ordinates the implementation of the three years of upgrading plan of information system to achieve the goal that information systems in various departments and departments run with unified authentication, unified data management, unified data sharing.

Strengthening government awareness of data sharing, data opening and data security. The awareness of data sharing and opening of government departments and managers should be enhanced through policy guidance and concept learning. In strict accordance with the laws and regulations of government data sharing and opening, the local government should strengthen the government data security management, eliminate enterprise and individual concerns about data collection and opening up, and effectively protect the legitimate rights and interests of the state, enterprises and citizens.

Development of big data industry. The local government should vigorously develop the big data industry, enhance the development and application level of the big data of the whole society, support big data industry technology innovation alliance construction, and while introduction of well-known domestic and foreign IT enterprises, actively encourage local IT enterprises becoming bigger and stronger.

Providing strong financial support to ensure the unified construction, sharing and application of the whole city. From the municipal level, a systematic study should be made on data sharing, data opening, and the feasibility, planning, design, standards and other aspects of the development and application of big data in various fields. It is recommended that to carry out the overall informatization project construction and application of the whole city, and to avoid the situation that each district has its own way and has independently funded the construction of information systems.

\section{Countermeasures and Approaches to Use Big Data to Improve Government Governance Capability}

On the basis of improving the top-level design of big data development and the connotation of government governance, as shown in Figure 2, the general strategy and path of using big data to improve 
local government governance ability can be carried out from the following four topics. The first is using big data to promote standardization and facilitation of government services. The second is using big data to promote precision of social governance. The third is using big data to facilitate the convenience of government commercial services. And the fourth is using big data to promote the scientific level of macro control.

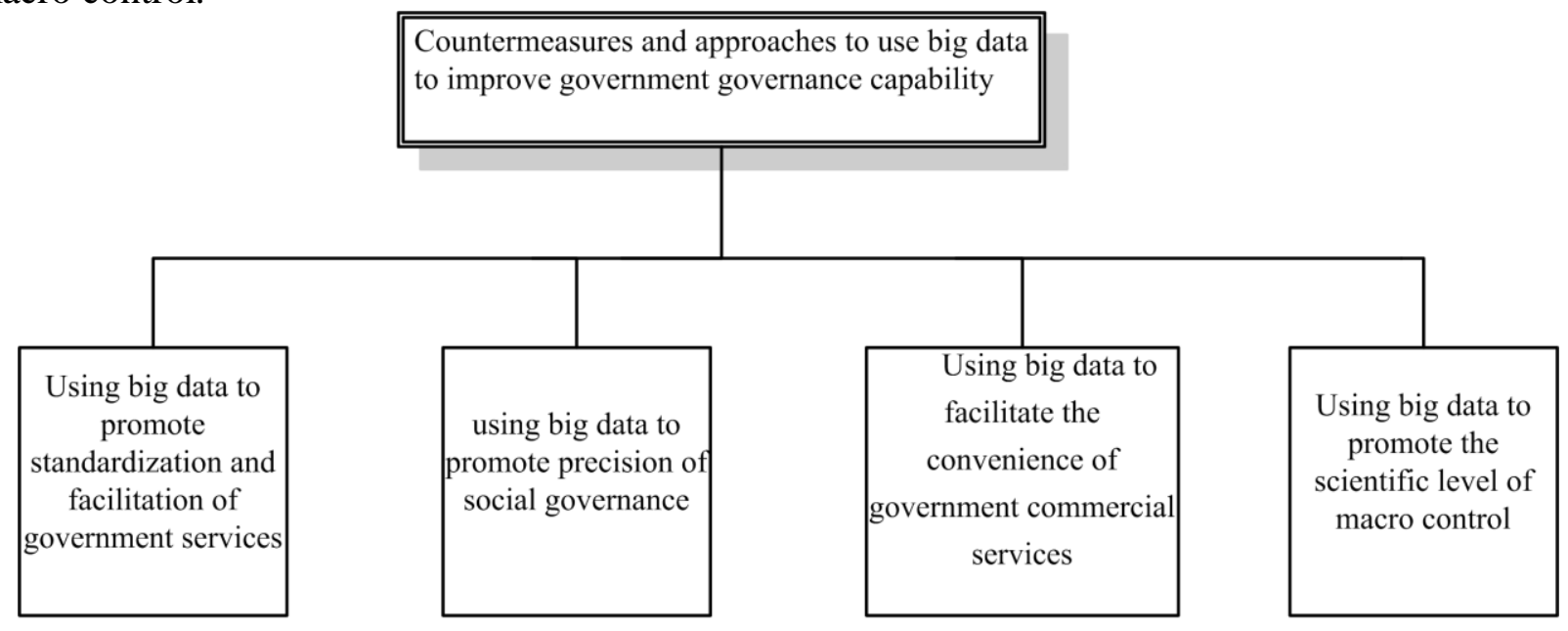

Figure 2. Framework for improving government governance capability with big data

The construction of "Internet plus government service platform". To promote the development and deep application of big data in the field of government affairs in Foshan, on the one hand, Foshan municipal government should actively encourage and support the departments to carry out the application of big data in their own fields with the actual conditions of their own units. On the other hand, in the original "One Door and One Net" government service platform based on the full use of big data technology, the government should construct the "Internet plus government service" big data ecosystem, to enhance the capability, quality and efficiency of government services. The main tasks are including establishment and application of standard specification, unified specification "one window acceptance", deep and perfect application mode of "complete all the affairs on the same network", full implementation of "the use of uniform identity numbers for applications", accelerating the construction of "my space", and promoting the city's major data services in the field of government services.

Construction of social governance platform based on big data.The municipal government should apply cloud computing, big data, Internet of things and mobile Internet and other new generation of information technology, and Integrate the information resources of each department in the social governance work, optimize grassroots grid inspections, services and law enforcement forces based on grid management, and then set up a unified social management and social services platform including the city, district, town, and community four levels to enhance the modernization level of grassroots governance capability. The main tasks are including establishment of social governance platform construction leading body, community grid service and management model, decision analysis support system and expanding the add-on functions' development.

Construction market subject service and regulatory platform based on big data. The municipal government should make full use of the advanced concept, technology and resources of big data to strengthen the service and supervision of market participants grasp the general and individual needs of different industries and different types of enterprises, actively provide more targeted services to promote sustainable development of enterprises.

Construction of macro-economic monitoring platform based on big data. The municipal government should comprehensively use government statistics and various social data to establish a macro-economic monitoring platform based on big data and to promote macroeconomic regulation and control innovation. The main tasks are including building a macro monitoring and forecasting system with local characteristics based on traditional statistical data and large data fusion on the internet, 
construction monitoring decision analysis system and building the city's manufacturing big data platform.

\section{Conclusions}

In the use of big data to enhance the governance capacity, the first thing is to design top-level strategic goals of local development big data and then develop big data further applications in the field of government management. The third is to choose the fields which conditions are ripe and big data can enhance the governance capacity obviously, such as social governance, government service, commercial service and macro-control etc. The goal is to establish a management mechanism that uses data to speak, to make decisions with data, to manage with data, and to innovate with data, to promote the government management concept and social governance model progress, to promote the standardization and facilitation of government services, the precision of social governance, the convenience of commercial services, the scientific regulation of macro-control, and the modernization of government governance capability.

\section{Acknowledgements}

This work is completed under the support of the "Foshan Social Science Plan Project in 2017 "(No. 2017-YB01).

\section{References}

[1] L. Zhang, Y. Li, Use New Information Technology to Boost the Modernization of Government Governance Capability. E-Government, Vol.12(2015)No.1,83-89.

[2] G. Chen, H. J. Wu, Y. F. Yang, E-government: a New Approach to the Modernization of Government Governance Capability. E-Government,Vol.11(2014),No.8,11-18.

[3] L. J. Chen, Research on the Building of Modernization Governance Ability on the Era of Big Data. Journal of North China University of Water Resources and Electric Power (Social Science Edition), Vol.31(2015), No2,43-45.

[4] F. Yuan, Research on the Realization Path of Boosting Government Governance Capability with Big Data. Journal of Hebei Normal University (Philosophy and Social Sciences Edition), Vol.38(2015),No.6,151-156.

[5] D. Sheng, Study on the Capability Improving of the Local governance in the Perspective of the Big Data (MS., Xiangtan University, China 2015), 6-12.

[6] X.Y. Xin, Three Basic Issues to Promote the Modernization of the National Governance System and Governance Capability. Theoretical Investigation,Vol.31(2014),No.2,27-31.

[7] W.L. Wu, X. D. Tang, Thinking about Promoting the Modernization of Government Governance Ability. Public Administration \& Law,Vol.23(2014),No.9,9-13.

[8] X.C. Lin, On the Modernization Ways of the Local Governance Capacity. Public Administration \& Law, Vol.24(2015),No.4,6-12.

[9] Q. Y. Yang, The Rational Interpretation of the Modernization of the Government Governance Capacity. Chongqing Social Sciences, Vol.27(2016),No.2,29-39.

[10] P. Q., Wang, The Inherent Meaning and Interrelationship of State Governance, Government Administration and Social Governance. Sociological Review of China, Vol. 2(2014) No.3, 12-20. 